\title{
Research in India: success through collaboration
}

\author{
R. Thara \& R. G. McCreadie
}

\section{An Indian's view}

Those contemplating research in developing countries should bear in mind the following: the collective wisdom of both foreign and local investigators should be pooled to determine the most appropriate research questions and ethical obligations. Several collaborative research programmes launched by the World Health Organization (WHO) have shown that it is eminently possible to engage in high-quality cross-cultural research, and many of these studies have generated a wealth of data from developing countries. Rigorous and highly sophisticated studies are possible in the developing world (Wilson, 1990). At the Schizophrenia Research Foundation (SCARF) we have had several opportunities to collaborate successfully with researchers both within and outside India (Eaton et al, 1995; Thara \& Eaton, 1996). This success has largely been due to mutual respect for one another's expertise and role with no room for patronisation and condescension.

\section{SCARF}

The Schizophrenia Research Foundation (India) in Chennai (formerly Madras) is a voluntary, non-profit organisation which, during the past 14 years, has been engaged in research, and the rehabilitation of those suffering from schizophrenia. We run an outpatient department and day care centre in the city and two residential rehabilitation centres in the suburban areas with a bed strength of 75 . Community outreach programmes in rural areas have been funded by international organisations such as the International Development Research Centre (Canada) and OXFAM. These programmes include delivery of mental health care to rural areas, rehabilitation using indigenous models, awareness programmes and research.

\section{The patients}

Our collaborative research programmes have largely been conducted with patients attending the SCARF centre in the city and the rural, community programmes. The latter have been a particularly rich source of 'never-treated' patients, the main patient group that $\mathrm{Dr} \mathrm{McC}$ readie and I have been studying. An area where many of our patients were examined is Thiruporur, about 50 miles from the city of Chennai. SCARF has been working here during the past 8 years. A fortnightly outpatient centre caters to nearly 100 villages around Thiruporur covering a population of 100000 . Despite this, we still find a large number of chronic mentally ill patients who have never been treated. The fact that a large number of people with mental illness do not seek treatment can be accounted for by the poverty and high rate of illiteracy and magicoreligious explanatory models of mental illnesses, compounded by the lack of nearby mental health treatment facilities. This area has two religious healing centres - $a$ Hindu temple and a Muslin place of worship - both of which offer treatment for the mentally ill. studies_of course and outcome and social disabilities of schizophrenia. Robin McCreadie is Director of Clinical Research and a consultant psychiatrist at Crichton Royal Hospital (Dumfries DG1 4TG). He is interested in biological and epidemiological aspects of schizophrenia and has published extensively on the Nithsdale cohort of patients with schizophrenia. 


\section{Collecting the data}

Many untreated patients are extremely poor and live in impoverished states. They often live in remote villages with little access to public transportation. Even if available, they are unable and unwilling to spend on transport to reach our out-patient centre. Research on explanatory models of illness completed a couple of years ago revealed that most of them had a traditional magico-religious model resulting in their easier acceptance of such modes of treatment (Thara et al, 1998).

A typical working day for the researchers would begin with a van ride starting at about 9 am covering a distance of 60-100 miles per day, sometimes on dusty and ill-paved roads. Since the villages in which these patients lived were widely dispersed, we spent $80 \%$ of the day travelling. The monsoons did not make it easier, messing up the muddy roads and making accessibility that much more difficult. When we alighted at a place, there was often a group of people, especially children, surrounding the van. They were only too keen to help and chip in their bit of information about the patient or even other potential patients. Confidentiality was non-existent and everybody in the village knew of the problems of everybody else. The average day ended at about 8 or $9 \mathrm{pm}$ when we would return to the city.

Locating the untreated patients with psychosis was easier than convincing them to take part in our research programmes. The incentive of treatment itself was not attractive, since in many cases, their families were reluctant to accept medical interventions. They had got so used to the state of the patient - whether it was inactivity, unproductivity, abnormal behaviour and sometimes even occasional violence - that any change seemed to provoke anxiety in the patients and family members. At times, even on repeated visits, we saw patients, especially some women, remaining seated in the same spot, with their eyes fixed suspiciously on any stranger. Food and drink were taken to them and quite often they would have to be persuaded to eat. Many of them were in a state of debility and malnutrition. About $30 \%$ of those identified refused to participate in the study, and around $10 \%$ were too ill - violent and kept isolated - or too suspicious.

After two years of working intensively with nevertreated patients, we found that even a great degree of persuasion resulted in only about $20 \%$ of this sample seeking treatment, or rather agreeing to take medicines. The other $80 \%$ chose to remain untreated. This decision was usually that of the families who had learnt to manage the ill relative and did not want the delicate balance to be tilted by medication. At other times, the patients refused to have anything to do with us.
Enlisting cooperation became more tricky when we had to draw blood or get them to come for investigations, such as magnetic resonance imaging (MRI). There is a strong belief that loss of blood can lead to 'weakness' and even the offer of a supplement of iron tablets did not help much in some cases. MRI was a particularly anxiety-provoking procedure, and the long travel to the city and the strange looking equipment in the MRI centre presented a totally alien and discomforting environment.

\section{Conclusion}

Despite all the factors mentioned above, it must be said that the overall cooperation and support from the patients, families, local community leaders and the health workers in that area who identified the cases was phenomenal. This is partly because of the credibility which SCARF had established in those areas as an organisation offering mental health care. The knowledge of several persons in the community, and the unique doctor-patient relationship which exists in many developing countries, had improved sufficiently to resume work. The role of the health workers drawn from the local community to identify and mobilise cases must be acknowledged. This reinforced our view borne from our experience that the critical ingredient of the effectiveness and efficiency of any programme, whether it be service delivery or research, is dependent on the base of community support and family involvement. This is particularly relevant in the developing world where over $90 \%$ of people with mental illness live with their families.

\section{A Scot's view}

\section{Getting started}

As the plane made its descent into Madras (now Chennai) in late October 1994, the British Airways pilot said 'Happy Diwali'*. I did not know what he meant. On my first visit, my ignorance of Indian culture was great; no doubt Dr Jim Birley would have been severely critical (Broadhead et al, 1999, this issue).

However, my knowledge of the unit where I was to work over the next month, or rather of the people who worked in it, was somewhat better - and this I learnt from published psychiatric literature. Earlier

\footnotetext{
*Diwali: a major Hindu religious festival honouring Lakshimi, the goddess of wealth. It is marked by feasting, gifts and the lighting of lamps.
} 
that year I had read, and been impressed by, a review of schizophrenia in India (Thara et al, 1993). I wanted to take forward my work on movement disorders in never-treated patients with schizophrenia, which I had carried out in Nigeria (McCreadie \& Ohaeri, 1994); these patients were on average middle-aged, and I now wanted to examine never-treated, elderly patients.

It is a sad fact that if a country has few psychiatric resources, then many patients will remain untreated. Would this be the case in India? The answer was yes, but as I soon realised, that was just the beginning of the story - a story which continues to the present day.

\section{The protocol}

I started corresponding with Dr Thara: I sent her copies of papers I had published to establish my credentials, and a tentative proposal. After quite a bit of to-ing and fro-ing, a draft protocol was agreed. I made it clear right from the start that I did not want simply to be someone who wrote a protocol, waited for the results to come in and then published. I wanted my contribution to be very much 'hands on'. In any research study, helping to collect the data is always a salutary experience, and, I am in no doubt, gives you greater 'street credibility'.

The final details of the project were hammered out in the headquarters of SCARF, in the suburbs of Chennai. The fact that I did not speak the local language (Tamil), but none the less wanted to collect data, lead, serendipitously, to a rigorous study design. It was decided that I would examine all the patients with schizophrenia for movement disorders, blind to their medication status (and, in fact, blind in the majority of cases to their illness status). The examination of movement disorders using the Abnormal Involuntary Movements Scale (AIMS; US Department of Health, Education and Welfare, 1976) required little verbal communication, but where it was necessary, either the patient had some English or Dr Latha, clinical psychologist, acted as interpreter. It was decided that Dr Thara and her psychiatrist colleagues would examine the mental state of patients, blind to their movement disorder status.

\section{Accommodation}

A large Indian city is impossible to describe; you have really got to go there and be overwhelmed by the noise, colour and sheer busyness of the place. My accommodation in Chennai for the next four weeks was a four-star hotel, a short walk from the seafront. After a day in the field, returning to an air-conditioned room with access to a shower, was for me (Western, middle aged, middle class) not a luxury, but a necessity.

\section{Collecting data}

I had not taken into account on my first visit that it was the monsoon season. Torrential rain and cyclones created havoc in the city and countryside which made travel difficult, and at times impossible. I learned another lesson about research in India be patient. Things will eventually get done, but they can take time.

The never-treated patients were mainly in the countryside. Medical services of any kind were virtually non-existent. The poverty was extreme. But everywhere I went I was treated with the utmost courtesy (and curiosity). I felt safer in and around Chennai than in and around Glasgow.

\section{Ethics}

The fact that we were recruiting never-treated patients and examining them for movement disorders could have led to ethical problems, but it did not. As Dr Thara has pointed out, this was because after examination, all patients were offered free medication. Although there is an Indian Mental Health Act, it is hardly ever applied to rural patients; if a patient does not want medication, then he or she cannot be forced by law to take it. However, I suspect family pressures acted in a number of instances to persuade patients to take antipsychotic drugs.

\section{Money}

Research costs money, but by Western European standards it costs considerably less in India. Also, if your research and clinical work overlap, costs can be kept to minimum. I raided my departmental research fund - a modest fund built up over the years mainly by two or three phase III drug studies. This helped to pay the main expenses and the salary of a social worker in Chennai whose main job for a couple of months was to identify never-treated patients in and around Chennai before I arrived. I took a month off work in Scotland (two weeks holiday leave, two weeks study leave) and paid my own air fare and hotel expenses. Dr Thara and her psychiatric colleagues combined their everyday clinical work with the research assessment of patients, and Ms Zarina, the Administrative Assistant at SCARF, among her many duties, made sure that the doctors and patients were in the right place at the right time. The whole thing probably 
cost less than $£ 2000$. The lesson to be learnt; good clinical research can be done on the cheap, not only in the UK, but also in India.

\section{The results}

During the month I was there, largely through the determination and sheer hard work of the SCARF team, we examined over 300 individuals, patients and control subjects.

We were pleased that we had traced and examined so many people, delighted that our paper was accepted by the British Journal of Psychiatry (McCreadie et al, 1996) and elated that it was selected by the Lancet as one of the five key publications in psychiatry in 1996 (Friedman \& Wiechers, 1996).

\section{What is happening now?}

There are no half-measures about India. You either like it or you do not: I do. Fired up with the success of our first project, we were determined to do more. I have visited India once or twice each year since then. We have published another study on cognitive aspects of never-treated patients (McCreadie et al, 1997), and completed a study on free-radical production in treated and never-treated patients with chronic schizophrenia. And we have embarked on our most ambitious project yet: a study which I believe could not be carried out anywhere in the word but in Chennai. We are scanning (MRI) nevertreated patients, with and without movement disorders, to find out whether there are differences in brain structure in the two groups. Also, blood samples are being taken, DNA extracted and genetic material examined for variants of the dopamine $D_{3}$ receptor gene. Why only Chennai? Well, I do not know of anywhere else in the world that has a centre of international repute for research into schizophrenia, large numbers of never-treated patients with schizophrenia, and local access to MRI and DNA extraction.

\section{Conclusions}

I have found my research activities in India one of the most satisfying experiences in my psychiatric
Box 1. Lessons to be learned

There is no room on either side for patronisation and condescension

For research to be successful, the involvement of the patient's family is essential

The Western researcher must have a 'handson' approach

Good clinical research can be done 'on the cheap

career. Research can be done by a Westerner in India. What you need is a good idea, a little bit of money, and, most of all, a clear understanding that the project is carried out by equals.

\section{References}

Broadhead, J., Piachaud, J. \& Birley, J. (1999) Helping to promote pschiatry in less developed countries. Advances in Psychiatric Treatment, 5, 213-220.

Eaton, W. W., Thara, R., Federman, B., et al (1995) Structure and course of positive and negative symptoms in schizophrenia. Archives of General Psychiatry, 52, 127-134.

Friedman, L. \& Wiechers, I. R. (1996) The brain hallucinates and gets caught in the web. Lancet, 348 (suppl. II), 21.

McCreadie, R. G. \& Ohaeri, J. (1994) Movement disorders in never and minimally treated Nigerian schizophrenic patients. British Journal of Psychiatry, 164, 184-189.

- Thara, R., Kamath, S. et al (1996) Abnormal movements in never-medicated Indian patients with schizophrenia. British Journal of Psychiatry, 168, 221-226.

-, Latha, S., Thara, R., et al (1997) Poor memory, negative symptoms and abnormal movements in never treated Indian schizophrenic patients. British Journal of Psychiatry, 171, 360-363.

Thara, R., Padmavati, R. \& Nagaswami, V. (1993) Schizophrenia in India. International Review of Psychiatry, 5, 157-164.

- \& Eaton, W. W. (1996) Outcome of schizophrenia: the Madras longitudinal study. Australian and New Zealand Journal of Psychiatry, 30, 516-522.

-, Islam, A. \& Padmavati, R. (1998) Beliefs about mental illness - a study of a rural South Indian population. International Journal of Mental Health, 27, 70-85.

Wilson, S. (1990) Alcohol research in developing countries: possibilities and limitations. NAD-PUBL, 18, 15-27.

US Department Of Health, Education \& Welfare (1976) Abnormal Involuntary Movements Scale (AIMS). In ECDEU Assessment Manual (ed. W. Guy) pp.534-537. Rockville, MD: US Department of Health, Education and Welfare. 